OPEN ACCESS

Edited by:

Ye Htun Oo,

University of Birmingham,

United Kingdom

Reviewed by:

David William Scott,

Uniformed Services University of the

Health Sciences, United States

Megan K. Levings,

University of British Columbia, Canada

Richard Taubert,

Hannover Medical School, Germany

*Correspondence:

Yasmin R. Mohsen

yasmin.mohseni@kcl.ac.uk

Giovanna Lombardi

giovanna.lombardi@kcl.ac.uk

Specialty section:

This article was submitted to Alloimmunity and Transplantation,

a section of the journal

Frontiers in Immunology

Received: 24 March 2020

Accepted: 16 June 2020

Published: 24 July 2020

Citation:

Mohseni YR, Tung SL, Dudreuilh C,

Lechler RI, Fruhwirth GO and Lombardi G (2020) The Future of

Regulatory T Cell Therapy: Promises and Challenges of Implementing CAR Technology. Front. Immunol. 11:1608

doi: 10.3389/fimmu.2020.01608

\section{The Future of Regulatory T Cell Therapy: Promises and Challenges of Implementing CAR Technology}

\author{
Yasmin R. Mohseni ${ }^{1 *}$, Sim L. Tung ${ }^{1}$, Caroline Dudreuilh ${ }^{1}$, Robert I. Lechler ${ }^{1}$, \\ Gilbert O. Fruhwirth ${ }^{2}$ and Giovanna Lombardi ${ }^{1 *}$
}

\begin{abstract}
${ }^{1}$ Peter Gorer Department of Immunobiology, MRC Centre for Transplantation, School of Immunology and Microbial Science, King's College London (KCL), Guy's Hospital, London, United Kingdom, ${ }^{2}$ Imaging Therapies and Cancer Group, Department of Imaging Chemistry and Biology, School of Biomedical Engineering and Imaging Sciences, King's College London, London, United Kingdom
\end{abstract}

Cell therapy with polyclonal regulatory $\mathrm{T}$ cells (Tregs) has been translated into the clinic and is currently being tested in transplant recipients and patients suffering from autoimmune diseases. Moreover, building on animal models, it has been widely reported that antigen-specific Tregs are functionally superior to polyclonal Tregs. Among various options to confer target specificity to Tregs, genetic engineering is a particularly timely one as has been demonstrated in the treatment of hematological malignancies where it is in routine clinical use. Genetic engineering can be exploited to express chimeric antigen receptors (CAR) in Tregs, and this has been successfully demonstrated to be robust in preclinical studies across various animal disease models. However, there are several caveats and a number of strategies should be considered to further improve on targeting, efficacy and to understand the in vivo distribution and fate of CAR-Tregs. Here, we review the differing approaches to confer antigen specificity to Tregs with emphasis on CAR-Tregs. This includes an overview and discussion of the various approaches to improve CAR-Treg specificity and therapeutic efficacy as well as addressing potential safety concerns. We also discuss different imaging approaches to understand the in vivo biodistribution of administered Tregs. Preclinical research as well as suitability of methodologies for clinical translation are discussed.

Keywords: Tregs (regulatory T cells), transplantation, CAR (chimeric antigen receptor), cell therapy, autoimmunity, regulatory, antigen specific

\section{INTRODUCTION}

Regulatory T cells (Tregs) are a subset of $\mathrm{T}$ cells that function to maintain homeostasis and prevent autoimmunity (1). Tregs make up $5-10 \%$ of the $\mathrm{CD} 4^{+} \mathrm{T}$ cell population (2) and are characterized by co-expression of CD4, CD25, the transcription factor Forkhead box protein 3 (FOXP3) and low levels of CD127. Although conventional human T cells (Tconv) can transiently express FOXP3, high FOXP3 levels and demethylation of the Treg specific demethylated region (TSDR), a conserved region within the FOXP3 gene, are distinct features of Tregs (3). The importance of FOXP3 in Tregs is supported by the evidence that mutations in the FOXP3 locus lead to Treg dysfunction and severe autoimmunity, as was first identified in Scurfy mutant mice (4) and the immunodysregulation polyendocrinopathy enteropathy X-linked syndrome (IPEX) in humans (5). 
Tregs are divided in thymus-derived (tTregs) and peripheralderived Tregs (pTregs) (6). During T cell development, those naïve $\mathrm{CD} 4^{+} \mathrm{T}$ cells receiving an intermediate TCR signal are driven to differentiate into Tregs-the quantitative difference in strength of such signal is thought to determine Tconv cell or Treg lineage commitment (7). Peripheral Tregs develop when FOXP3 ${ }^{-}$Tconv encounter repeated stimulation to non-self antigens or receive inadequate co-stimulation, as well as exposure to IL-10 and TGF- $\beta$ (8).

Tregs suppress the immune system by different mechanisms including contact-dependent mechanisms, through CTLA-4 engagement for example, and contact-independent, such as the release of cytokines e.g., IL-35 or IL-10 [reviewed in (9)]. Given their proven role in preventing autoimmune diseases, Tregs have obvious potential in the promotion of tolerance. Although human Tregs constitute a small proportion of circulating CD4 ${ }^{+}$ $\mathrm{T}$ cells, they are attractive candidates for immunotherapeutic purposes given that they can be isolated, manipulated and expanded in large numbers in vitro. Tregs can be applied in the treatment of autoimmune diseases and in the prevention of transplant rejection and graft vs. host disease (GvHD).

\section{ADOPTIVE TREG THERAPY: FROM POLYCLONAL TO ANTIGEN SPECIFIC}

The first phase I clinical trials investigating the safety of adoptive transfer of Tregs were in the treatment of bone marrow patients to prevent GvHD, NCT00602693 (10-12). These trials demonstrated the safety and efficacy of Treg therapy. Autologous polyclonal Tregs have been infused in patients with type 1 diabetes (T1D) as well, demonstrating again the safety and feasibility of adoptive Treg therapy in this disease setting [ISRCTN06128462, (13) and NCT02691247, (14)]. Treg therapy has reached the organ transplant arena as well (UMIN-000015789 and NCT02088931) $(15,16)$. We have demonstrated the safety of adoptively transferred Tregs in two phase I clinical trials in liver (ThRIL, NCT02166177) and kidney (ONE study, NCT02129881) transplant patients $(17,18)$.

However, whilst the above clinical studies have shown the potential of polyclonally expanded Tregs, we and others have demonstrated the superiority of antigen-specific Tregs compared to polyclonal Tregs in animal models. Tang et al. successfully isolated and expanded Tregs from a transgenic mouse expressing a TCR specific for an islet antigen, and showed that antigenspecific Tregs prevented and even reversed diabetes in nonobese diabetic mice $(19,20)$. More recently, human Tregs were modified in vitro to generate Tregs specific for donor antigens, by co-culturing Tregs with donor-derived dendritic cells (DCs) or $\mathrm{B}$ cells $(21,22)$. The superiority of donor-specific human Tregs compared to polyclonal Tregs was demonstrated in vitro and in vivo in a humanized mouse model of human skin transplant $(21,22)$. Similar results were obtained in vitro by Zheng et al. as they demonstrated that mature B cells were better stimulants than immature DCs in generating Tregs expressing higher levels of FOXP3 and CD25, and with superior suppressive capacity (23). Already as part of the ONE Study (NCT02129881) kidney transplant patients have been treated with donor-specific Tregs and additional clinical trials in transplant patients are investigating the use of donor-reactive Tregs [reviewed by (9)].

Evolving from the use of APCs to generate Tregs with specificity for the target antigen, research has shifted toward gene transfer. Wright et al. transduced Tregs with a TCR specific for ovalbumin (OVA) and restricted by the MHC-class II $\mathrm{A}^{\mathrm{b}}$. These Tregs transferred in vivo were able to inhibit a well-established antigen induced arthritis in which mice were immunized with methylated BSA (mBSA) followed by intra-articular knee rechallenge with mBSA to induce $\mathrm{T}$ cell-mediated tissue damage. The OVA-specific Tregs were able to decrease inflammation to the knee but only when OVA was present (24). In the same study a similar effect was obtained with $\mathrm{CD} 4^{+}$Tconv transduced with the same TCR and FOXP3; engineering CD $4^{+}$Tconvs to express FOXP3 endows them with a suppressive function (24). We generated Tregs from C56BL/6 recipient mice specific for donor $\mathrm{BALB} / \mathrm{c}$ antigen by retroviral transduction of a TCR specific for a peptide derived from MHC-class I $\mathrm{K}^{\mathrm{d}}$ and presented by MHCclass II $\mathrm{A}^{\mathrm{b}}$. We demonstrated that Tregs with this specificity contributed to the indefinite survival of $\mathrm{BALB} / \mathrm{c}$ heart transplants into B6 (25). Brusko et al. transduced human Tregs with a TCR specific for the melanoma antigen tyrosinase and restricted by HLA-A*0201. Tregs were expanded in vitro and administered in vivo in a tumor model. They were able to inhibit effector $\mathrm{T}$ cells leading to tumor growth (26). Hull et al. transduced Tregs with two TCRs isolated from islet-specific and influenzaspecific $\mathrm{CD}^{+} \mathrm{T}$ cell clones. The authors showed that the ability of the islet antigen-specific TCRs to induce Treg mediate antigen-specific suppression in vitro was significantly lower when compared to what was achieved using TCRs with specificity for viral antigens (27). More recently, Kim et al. transduced Tregs with a TCR specific for myelin basic protein (MBP) isolated from a $\mathrm{T}$ cell clone derived from a multiple sclerosis patient (28). These Tregs suppressed MBP-specific T effector in vitro and in vivo they ameliorated experimental autoimmune encephalitis (EAE) (28).

As an alternative to the use of Tregs as cell therapy, several studies have looked at generating Tregs by manipulating $\mathrm{CD}^{+}$Tconv cells to express FOXP3. In hemophilia, up to one third of patients receiving therapeutic factor VIII (FVIII) infusions develop neutralizing antibodies. Herzog et al. transduced $\mathrm{CD}^{+}{ }^{+}$Tconv with FOXP3 and FVIII. Following administration of these cells to hemophilia A mice, the formation of neutralizing antibodies to FVIII was suppressed (29). In an animal model of type 1 diabetes, Jaeckel et al. transduced isletspecific CD4 ${ }^{+}$Tconv with FOXP3. These cells were activated in the pancreatic lymph nodes and reversed recent-onset diabetes (30). Beavis et al. showed that the ectopic expression of FOXP3 in pathogenic synovial $\mathrm{T}$ cells from rheumatoid arthritis patients attenuated their function (31). Loser et al. showed the efficacy of FOXP3-transduced Tconv in suppressing contact hypersensitivity responses in mice. Moreover, these cells diminished autoimmune dermatitis in CD40L transgenic mice and cleared antinuclear antibodies (32). These studies are seminal demonstrating the acquisition by Tconvs of a suppressive profile, equally research within immunoregulation has lately been more focused toward enhancing Tregs for cell therapy. 
An alternative method to confer specificity to Tregs is by transducing these cells with chimeric antigen receptors (CAR). CAR technology offers some advantages over TCR engineering. These include bypassing HLA restriction upon activation of $\mathrm{T}$ cells expressing CARs, increased specificity through the requirement of co-receptor signaling, and the targeting flexibility of CARs (any soluble or surface multivalent antigen can serve as target). In the following sections we focus on CARs to enhance Treg therapy.

\section{CHIMERIC ANTIGEN RECEPTORS: LESSONS FROM CANCER THERAPY}

CARs have been developed and by now clinically implemented in oncology to treat certain cancers. They represent an approach to fine-tune adoptively transferred therapeutic $\mathrm{T}$ cells to target specific antigens by-passing MHC-restriction and thereby enable these therapeutic cells to attack the cancer. CARs are artifical molecules engineered into target cells. They are composed of an extracellular target-recognition domain (e.g., a scFv specific for the target antigen), hinge and transmembrane domains, and intracellular signaling domains to propagate activation signals as a consequence of extracellular target engagement. CARs are less sensitive in response than TCRs due in part to the number of molecules involved in the TCR machinery, i.e., CD4/CD8 co-receptors, immunoreceptor tyrosinase-rich activation motifs (ITAMs), and subunits within the receptor complex (CARs require 100-10,000 molecules per target cell while TCRs need $<10$ molecules per target cell) but bind with higher affinity than the TCR; although studies have investigated increasing CAR sensitivity by incorporating lower affinity single-chain variable fragment $[\mathrm{scFv} ;(33,34)]$.

\section{From CAR-T Cells in Oncology to CAR-Tregs}

The first CAR was composed of a CD3 $\zeta$ chain of the TCR/CD3 $\zeta$ complex, but $\mathrm{T}$ cell activation was neither persistent in vivo, nor sustained and the T cells did not proliferate sufficiently (35, 36). Second generation CARs contain an additional intracellular feature, a co-stimulatory domain, which has the purpose to potentiate the signaling response of the CAR. Several costimulatory domains including those from CD28, 4-1BB (CD137) and OX40 (CD134) molecules have been explored in CAR$\mathrm{T}$ cell therapy. Third generation CARs are composed of two different co-stimulatory molecules. Indeed it were second generation CARs that led to the breakthrough in cell-based cancer immunotherapy. In 2017, the FDA approved the first clinical products, tisagenlecleucel and axicabtagene ciloleuceltrademarked as Kymriah ${ }^{\circledR}$ and Yescarta-which are autologous CD19b-targeted CAR-T-cell immunotherapies for the treatment of B-cell acute lymphoblastic leukemia and B-cell lymphoma, respectively (37-39). CAR-T immunotherapies have the potential to be curative, but so far not all patients have responded and sometimes the effects were only temporary (39-41). CAR-T cell therapy has been also associated with severe/lifethreatening side-effects and fatalities during clinical trials (42,
43). Research into CARs specific for tumor-related antigens in hematological malignancies paved the way for the application of CARs in immunoregulation. CAR-T cells have been already applied to treat autoimmune disease. In an animal model of pemphigus vulgaris, which is a rare severe autoimmune disease in which blisters of varying sizes break out on the skin and mucous membranes, chimeric auto-antibody receptor (CAAR)$\mathrm{T}$ cells were generated with specificity for the keratinocyte adhesion protein Dsg3 (44). The CAAR-T cells exhibited specific cytotoxicity to anti-Dsg B cells in vivo without off-target toxicity (44). Although engineering CAAR-T cells may be effective in inhibiting some autoimmune diseases, Tregs can also be applied due to their powerful immunosuppressive and tolerancepromoting properties.

Tregs have been transduced to express CARs and tested in pre-clinical models of autoimmunity, GvHD and transplantation as well as colitis. Elinav et al. generated a transgenic mouse whose $\mathrm{T}$ cells including the Tregs expressed a CAR specific for 2,4,6-trinitrophenol. The adoptive transfer of CAR-Tregs to wild-type mice suffering 2,4,6-trinitrobenzenesulfonic acidinduced colitis was associated with significant amelioration of colitis and improved survival (45). The same group generated Tregs expressing a CAR specific for the human carcinoembryonic antigen (CEA). These Tregs markedly suppressed the severity of colitis in the CEA transgenic mouse, CEABAC, where colitis was induced by transfer of effector T cells specific for CEA (46). Another study used a CEA transgenic mouse to show that CEAspecific CAR-Tregs can inhibit allergic airway inflammation (47). More recently, Tenspolde et al. generated CAR-Tregs specific for insulin but despite them proliferating in response to insulin and being suppressive in vitro, these CAR-Tregs did not prevent spontaenous diabetes in mice; interestingly these cells persisted up to 4 months post adoptive transfer (48). Furthermore, in a mouse model of hemophilia A, Zhang et al. created Tregs expressing a $\mathrm{B}$ cell-targeting antibody receptor (BAR) containing the immunodominant FVIII C2 or A2 domains. The BAR-Tregs completely prevented anti-FVIII antibody development in FVIIIimmunized mice. They also demonstrated a direct effect on FVIII-specific B cells (49).

In transplantation, we and others have generated Tregs expressing an HLA-A2-specific CAR (A2-CAR-Tregs) (5052). We have shown that A2-CAR-Tregs were functionally superior compared to polyclonal Tregs in vitro and in vivo in a humanized mouse model of BRG mice bearing a human skin transplant reconstituted with 5:1 PBMCs to CAR-Tregs, assessed by histological analysis 5 weeks post adoptive transfer (51). Noyan et al. also demonstrated the efficacy of an A2CAR-Tregs in inducing indefinite survival of allogeneic human skin transplants in a humanized mouse model of NRG mice injected intraperitoneally with 7.5:1 PBMCs to A2-CAR-Tregs and graft survival was assessed (52). Similar A2 ${ }^{+}$CAR-Tregs were also shown to ameliorate xenogeneic GvHD (50). Lately, the Levings group produced a panel of humanized HLA-A2 CAR-Tregs and developed a method to map the specificity of CARs, showing that humanization reduced HLA-A crossreactivity (53). Recently, the same group also investigated the ability of murine HLA-A2 CAR-Tregs to prevent allograft 
rejection in immunocompetent mice (54). The results showed that these Tregs prolonged skin allograft survival and humural alloresponses but not in presensitised mice, suggesting HLAA2 CAR-Tregs are unable to inhibit memory $\mathrm{T}$ or $\mathrm{B}$ cell responses (54).

In the following sections we review the challenges for CARTreg therapy and discuss ways to improve CAR-Treg function, safety and specificity for clinical applications.

\section{CAR Co-stimulatory Endodomain Functions in T Cells}

Past studies have focused on optimizing the CAR co-stimulatory endodomain design to provide robust CAR-T cells for fighting cancer (55) of which a wide variety had been tested. For example, CAR co-stimulatory endodomains tested in $\mathrm{T}$ cells in addition to CD28 include 4-1BB, OX40, inducible $\mathrm{T}$ cell co-stimulator (ICOS) and CD27. Zhang et al. reported that 4-1BB co-stimulation plays an important role for memory $\mathrm{CD}^{+} \mathrm{T}$ cell proliferation ex vivo and is superior to CD28 costimulation in terms of generating antigen-specific $\mathrm{CD}^{+} \mathrm{T}$ cell (56). Transduction of $\mathrm{CD}^{+}(57)$ and of a mixture of $\mathrm{CD}^{+}$and $\mathrm{CD}^{+}$(1:1 ratio) (58) T cells with a CAR construct incorporating $4-1 \mathrm{BB}$ resulted in augmented T cell longevity. This was due to 4$1 \mathrm{BB}$ co-stimulation via the CAR decreasing the exhaustion rate of T cells induced by tonic CAR signaling (57). In another study, $\mathrm{Li}$ et al. showed that $\mathrm{CAR} \mathrm{CD}^{+}{ }^{+}$and $\mathrm{CD} 8^{+} \mathrm{T}$ cells with $4-1 \mathrm{BB}$ co-stimulatory endodomain improved $\mathrm{T}$ cell function via the NF$\kappa \mathrm{B}$ signaling pathway. Compared to the CD28 co-stimulatory domain, 4-1BB was more associated with the upregulation of anti-apoptotic proteins, which might explain their function in prolonging T cell longevity (59). Whilst OX40 activity enhanced $\mathrm{CD}^{+}{ }^{+}$and $\mathrm{CD}^{+}{ }^{+} \mathrm{T}$ cell expansion and survival, it also blocked thymic $\mathrm{CD}^{+}$Treg activity and antagonized the generation of inducible $\mathrm{CD}^{+}{ }^{+}$Tregs (60-62). However, OX40 activity upregulated anti-apoptotic Bcl-2 family members including Bcl$\mathrm{xL}, \mathrm{Bcl}-2$ and Bfl-l and molecules involved in the cell cycle such as survivin and aurora B kinase (63-65). Additionally, Hombach et al. found that $\mathrm{CD} 4^{+} \mathrm{T}$ cells transduced with a CAR containing an OX40 endodomain abrogated IL-10 secretion, even in conjunction with a CD28 co-stimulation domain, without impairing the other Teff functions, tipping the balance against suppression in cancer (66). Prior to that, the authors investigated the effect of OX40, 4-1BB, and CD28 CAR endodomains in $\mathrm{CD}^{+}{ }^{+}$and $\mathrm{CD}^{+}{ }^{+} \mathrm{T}$ cells, and determined that $\mathrm{CD} 28$ was the most potent at initiating a $\mathrm{T}$ cell response, and OX40 and 4$1 \mathrm{BB}$ sustained the response with OX40 outperforming the other two for the most prolonged time (67). Another co-stimulatory molecule expressed by $\mathrm{T}$ cells is ICOS, which is essential for $\mathrm{T}$ cell activation and proliferation (68). ICOS has a significant homology to CD28 and CTLA-4 $(69,70)$ but is not constitutively expressed on resting $\mathrm{T}$ cells but upregulated upon TCR and/or CD28 engagement $(69,71)$. Guedan et al. demonstrated that ICOS expression via CAR $\mathrm{CD}^{+}$and $\mathrm{CD}^{+} \mathrm{T}$ cells enhanced anti-tumor activity and promoted cell survival longer than 4-1BB or CD28 CAR-T cells (72). CD27 is essential for CD4 ${ }^{+} \mathrm{T}$ cell functions such as promoting antigen-specific cell expansion of naïve T cells and the generation of memory T cells (73). CD27 costimulation via CAR $\mathrm{CD}^{+}{ }^{+}$and $\mathrm{CD}^{+}{ }^{+} \mathrm{T}$ cells upregulates antiapoptotic Bcl-XL protein expression and resistance to antigeninduced apoptosis, leading to increased numerical expansion although it underwent equal cell division without CD27 (CD3ל alone). CD27 CAR-T cells may be better than CD28 CAR-T cells due to enhanced survival and accumulation thus quantitatively increased response (74).

However, whether expression of these co-stimulatory endodomains via CARs on Tregs enhances their function in a similar manner to those found in CAR-T cells is still to be elucidated.

\section{CLINICAL PRODUCTS OF CAR-T}

Engineering CAR-Tregs destined for the clinic involves different stages in the GMP facility that need to be optimized. Currently, GMP protocols rely on either magnetic isolation of total $\mathrm{CD} 4{ }^{+} \mathrm{CD} 25^{+}$Treg populations, or fluorescence-activated cell sorted (FACS) (75). It is advisable that for the generation of CARTregs the Tregs need to be highly pure to avoid any expansion of "contaminating" Teff. Delivering the CAR to the Tregs involves viral-based transfer (i.e., lentivirus or retrovirus) and although to date no safety concerns have been reported with genetically engineered $\mathrm{T}$ cells, using non-viral vehicles have been gaining traction, such as transposon/transposases (i.e., Sleeping beauty, piggyBac transposon) or gene-editing tools which will also be discussed (76). With respect to expansion, protocols already developed for polyclonal Treg infusion can be employed for CAR-Tregs. Alternatively, semi-automatic systems employed in CAR-T cell development such as rocking-motion bioreactors and static culture bags can be optimized for CAR-Treg expansion (77). The number of Tregs needed for therapy remains unclear and the doses of administered Tregs varied in different trials. We have injected polyclonal Tregs ranging from $10^{5}$ to $10^{7}$ cells $/ \mathrm{kg}$ bodyweight in the ThRIL and the ONE Studies $(17,18)$ The prediction is that fewer numbers of CAR-Tregs would be needed, although solid organ transplant trials employing antigen-specific Tregs have ranged up to $9 \times 10^{8}$ cells [for more details please refer to (9)].

\section{ENHANCING CAR-TREGS}

Engineering CAR-Tregs for clinical applications include boosting their potency, persistence, and safety. Given that CARs are composed of building blocks, modifying the scFv targeting moiety, or the intracellular co-stimulatory signaling domain has been a focus, and will be discussed herein. Additional payloads to the construct such as including safety switches or in vivo tracking modalities like imaging tracers are also discussed.

Like conventional $\mathrm{T}$ cells, Tregs express an array of different stimulatory and inhibitory receptors (78). However, the function of each of these receptors in Tregs may be different compared to conventional $T$ cells. Due to the various properties of different co-stimulatory molecules, it is unlikely that one particular co-stimulatory molecule can serve 
all therapeutically required purposes for CAR-Treg therapy. Therefore, it is likely that for optimal function and persistence of therapeutic CAR-Tregs will be different, perhaps simultaneous co-stimulation signals are required, and possibly at different time points.

\section{Optimizing CAR-Tregs for Universal Recognition and Function}

Most of the available studies in pre-clinical models of diseases have been focusing on mono-specific CAR-Tregs. Increasing the specificity of CAR-Tregs could boost their therapeutic efficacy, coined with the added advantage of Tregs functioning indirectly through bystander suppression. Different methods of implementing universal recognition of CAR-Tregs are reviewed.

The first option is to infuse a pool of CAR-Tregs with different specificities (Figure 1A). This has been tested by pooling monospecific CAR-T cells targeting CD19/CD123 for B-ALL and human epidermal growth factor receptor-2 (HER2)/IL-13R $\alpha 2$ for glioblastoma (79-81). However, this is logistically challenging, as expansion of autologous CAR-Tregs specific for different target antigens would be limited by the number of autologous Tregs available and the high numbers of antigens to target. Therefore, combinatorial antigen strategies or dual CAR-T cells have been developed (Figure 1B) using cells transduced with two different CARs with different antigen specificities and signaling domains $(79,80,82,83)$. The dual CAR-T cells were more efficient than pooled CAR-T cells in preventing antigen escape and demonstrated increased anti-tumor efficacy (79). Bi-specific CARs (or Tandem CAR) targeting two different antigens can also be used (Figure 1C) $(81,84,85)$, but limitations include mouse $\mathrm{scFv}$ immunogenicity, the cross-pairing of the variable light and heavy chains between different scFvs and limited viral vector package size (86). Developing a modular or universal CAR (UniCAR; Figure 1D) where the CAR utilizes a soluble connecting molecule to engage the antigen of interest is also another strategy (87). Cells of interest are indirectly connected to the UniCAR through a distinct targeting module, called CARadaptors [cf. (88)]. Therefore, a tailored control of the Treg activity is possible, as the activation of the UniCAR-Tregs is strictly dependent of the targeting module and changing the targeting module opens to universal applications. Koristka et al. showed that Tregs derived from patients with autoimmune conditions were successfully engineered with UniCARs with $4-1 \mathrm{BB} / \mathrm{CD} 3 \zeta$ intracellular domains and these UniCAR-Tregs were able to suppress patient-derived effector cell functions, as determined by luciferase-expressing PC3-PSCA cancer cells (87). A FITC-CAR-Treg has been described by Pierini et al., which allows the combination of any monoclonal antibody to the FITC-CAR, facilitating a customisable approach to targeting antigens. The efficacy of the FITC-CAR-Tregs was demonstrated by showing that the injection of $\mathrm{H}-2 \mathrm{D}^{\mathrm{d}}-\mathrm{mAbCAR}$-Tregs into $\mathrm{B} 6$ mice increased the survival of $B A L B / c$ skin and islet allograft as compared to isotype-mAbCAR-Tregs (89). These last approaches are quite promising and it is the first step toward off-the shelf therapies, which could help improving the deliverability and cost associated with these treatments.

\section{CAR Co-stimulatory Endodomain Function in Tregs}

Different co-stimulatory molecules provide different functions. Thus, it is unlikely that one particular co-stimulatory molecule can serve all therapeutic purposes required for CAR-Treg therapy. Therefore, it is likely that for optimal function and persistence of therapeutic CAR-Tregs, a particular costimulatory endodomain is chosen and used for the disease or health indication context that best benefits from this costimulatory endodomain. In addition, perhaps a combination of co-stimulation signals are required, and possibly at different time points to achieve a robust or efficient CAR-Treg therapy for patients.

The importance of the CD28 co-stimulatory domain in CARTregs has been demonstrated by various groups. MacDonald et al. demonstrated that alloantigen-specific HLA-A2-specific CD28 CAR-Tregs were superior to non-targeted CAR-Tregs at preventing xenogeneic Graft vs. Host disease (GvHD) (50). We used a CAR specific for HLA-A2 that did not have an endodomain signaling component $(\triangle \mathrm{CAR})$ but still contained the targeting domain (i.e., ScFV specific for HLA-A2) and showed that although they were less efficient compared to fully functional CD28 CAR-Tregs in vitro, in a humanized mouse model of human skin transplant, $\triangle \mathrm{CAR}$-Tregs offered greater graft protection than polyclonal Tregs but less than CD28 CARTregs. We concluded that CAR-Treg localization and activation via the TCR are important feature for their immunosuppressive capacity (51). Similarly, Noyan et al. showed that HLA-A2 specific CD28 CAR-Tregs prevented skin allograft rejection in a human skin transplant mouse model (52).

However, other co-stimulatory molecules expressed by Tregs could potentially enhance their function, stability (avoiding conversion to effector cells) and survival. To this end, Boroughs et al. performed a side-by-side comparison of CAR-Tregs expressing CARs encoding CD28 or 4-1BB endodomains. They found that CAR-Tregs with the CD28 endodomain maintained their inhibitory function whereas CAR-Tregs with the 4-1BB endodomain did not. Furthermore, only CD28 CAR-Tregs and not 4-1BB CAR-Tregs were effective suppressors of T-effector cells in vivo and were the most effective at inhibiting EGFR-CAR Teff mediated damage on $\mathrm{EGFR}^{+}$skin transplant (90). This is in contrast with what has been published with CAR-T cells, in which the $4-1 \mathrm{BB}$ endodomain but not the $\mathrm{CD} 28$ endodomain reduced CAR-T cell exhaustion resulting in enhanced CAR$\mathrm{T}$ cell persistence and longevity $(57,91)$. Despite several recent successes, the overall understanding of the mechanisms governing Treg stimulation remains somewhat limited. While the evidence base is rapidly increasing, more work will be required to gain insight into these precise mechanisms to generate optimized potent and long-term stable therapeutic Tregs.

\section{ENGINEERING BEYOND THE CAR}

\section{Enhancing the Safety Profile of CAR-Tregs}

In clinical trials patient safety is of the highest priority. With cellular therapy at the clinical trial phase it is not certain 


\section{A}

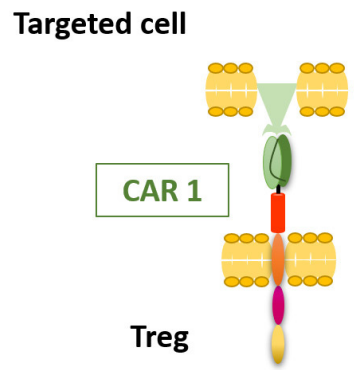

Targeted cell

B

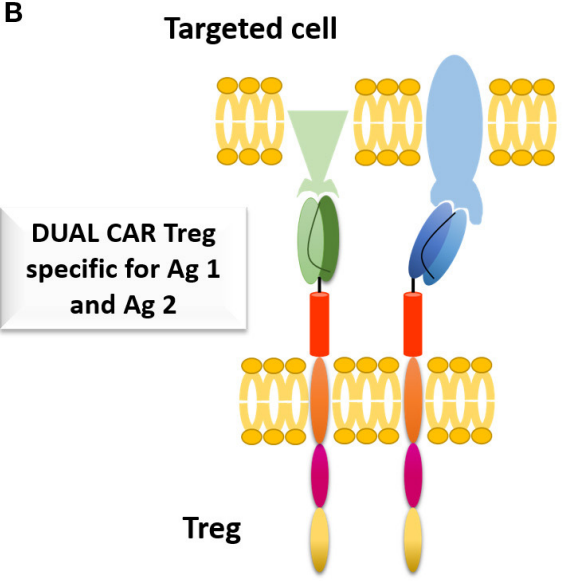

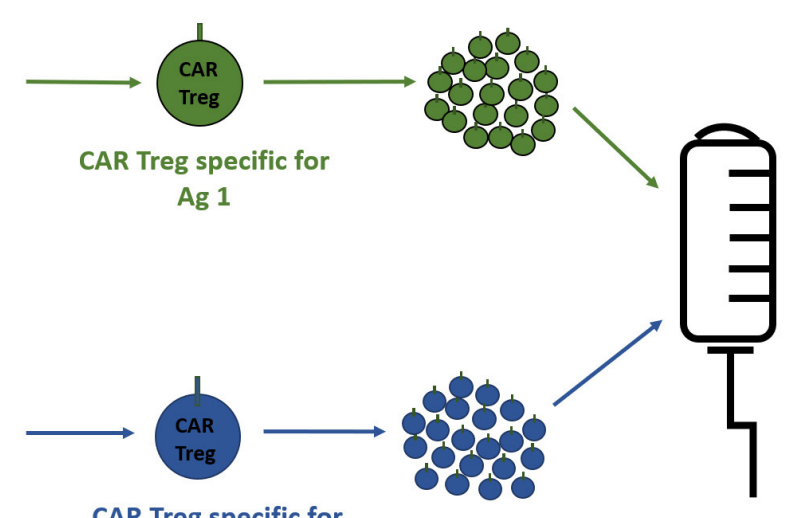

CAR Treg specific for Ag 2 c

Targeted cell

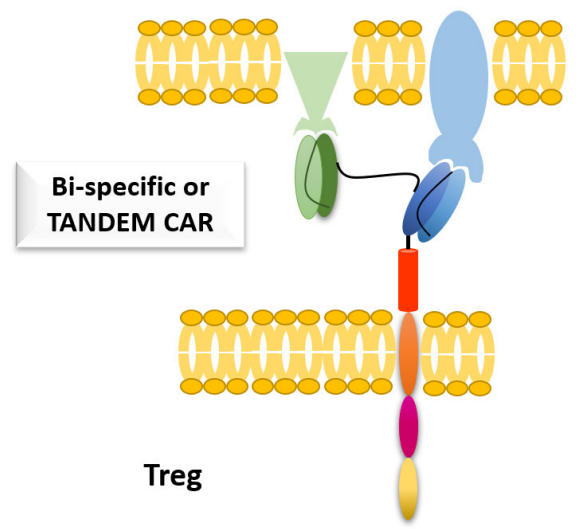

D

Targeted cell

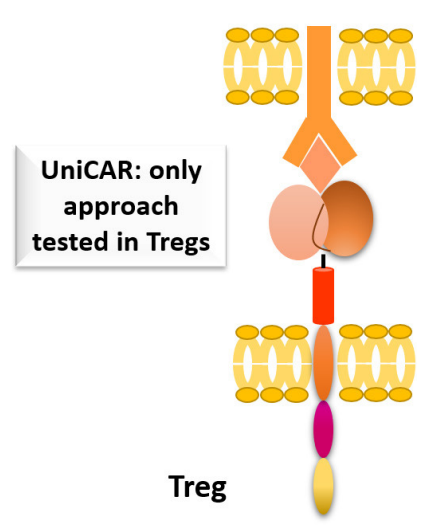

FIGURE 1 | Alternatives to CAR monospecificity. (A) Pooled antigen specific CARs against two different antigens. CAR1 targeting Antigen 1 (Ag1), displaying an anti-Ag1 scFV, a CD28 extracellular region, a CD28 transmembrane domain, a CD28 signaling domain and a CD3 $\zeta$ signaling domain, CAR2 targeting antigen 2 (Ag 2), with anti-Ag2 scFv. (B) Dual CAR - two different CARS connecting molecule to interact with the cell of interest. (C) Bi-specific or Tandem CAR-CAR able to interact with two different antigens. (D) Uni-CAR-using a connecting molecule to interact with the cell of interest. The CAR is displaying an anti-connecting molecule ScFv and the targeted cell has a receptor for the connecting molecule. Only approach tested with Tregs.

whether the therapeutic cells will reach their intended destination within the patient's body and thus off-target effects may occur (92-94). In the context of CAR-Tregs, if it were to function off-target it could ensue a situation in which the patient experiences pan-immunosuppression which leads to a reduced appropriate immune response against opportunistic infections and possibly cancer development. One way to control the life of these injected therapeutic cells in the patient is to include a suicide gene feature within these genetically modified therapeutic cells before injecting them back into the patient. Suicide genes are like a "safety switch" that permits selective death on expressing cells in the event of elevated toxicity by administration of an activating soluble pharmaceutical agent in the patient (92-94). Examples of suicide genes include surface proteins such as RQR8 (93) and huEGFRt (92) which can be recognized by monoclonal antibodies (mAbs). A potential drawback of mAbs-mediated suicide genes is that the concentrations required for efficient elimination may not be easily achieved due to accessibility of the mAbs to desired tissues.

Other suicide genes can be activated by small molecules such as the herpes simplex virus thymidine kinase (HSV1$t k$ ) and inducible caspase 9 (iCasp9) systems (94). HSV1$t k$ is a non-toxic enzymatic protein that converts pyrimidine 
and acycloguanosine nucleoside analogs for example ganciclovir into phosphorylated compounds that are toxic metabolites that presents as chain terminators and specifically kill transduced cells. This technology is widely used for cancer therapy (95). iCasp9 is a fusion of a modified human FK506 binding protein12 (FKBP12) with the catalytic domain of human caspase 9, and its conditional dimerization allows for its activity. iCasp9 has low potential immunogenicity and its function upon activation is specific to the transduced cells. Furthermore, iCasp9 maintains function in $\mathrm{T}$ cells overexpressing antiapoptotic molecules (94). These properties could promote the choice for iCasp9 as a safety feature element in CARTregs amongst other human $\mathrm{T}$ cell therapies. Di Stasi et al. published a study which enrolled five patients who had undergone stem-cell transplant for relapsed acute leukemia and treated with iCasp9-expressing $\mathrm{T}$ cells. With a single dose of the dimerising drug it eliminated more than $90 \%$ of the iCasp9-expressing $\mathrm{T}$ cells (96). The iCasp9 safety switch has been incorporated in second generation CAR-T cells used in clinical trials targeting GD2 for cancer treatment (NCT01822652, NCT02439788) (59). Another clinical trial using fourth generation CAR-T cell therapy also employed the iCasp9 technology (NCT02992210) (59).

Overall, it could be envisioned that the ideal CAR-Treg product would be armored with an array of efficient costimulatory domains and suicide genes.

\section{Reporters for Spatiotemporal in vivo Tracking}

The administration of live cell therapeutics including CAR-Tregs raises several important questions pertaining to cell therapy localization and relocalization over time, sites of activity and overall fate of administered cells. The existence of adoptively transferred cells can be demonstrated with highly sensitive methods based on blood samples. Cytotoxic T-cells have been shown by qPCR to be present years after administration in some patients (97). Administered Tregs have also been demonstrated to be present for a long time in the circulation of patients using a stable isotope labeling approach based on deuterium; polyclonal Tregs labeled with $\left[6,6-{ }^{2} \mathrm{H}_{2}\right]$ glucose were detected in the circulation of Type I diabetes patients for up to 1 year (14). Importantly, these methodologies suffer from not providing answers to questions relating to spatial localization, activity, and fate of the therapeutic cells at target sites. Non-invasive whole-body imaging would be a highly beneficial tool to answer all these questions in a spatiotemporal manner.

The field of in vivo cell tracking has re-gained new momentum through the development of adoptive cell therapies. The various cell tracking methodologies including a variety of experimental design considerations and caveats have recently been comprehensively reviewed (98), also in the context of tracking $\mathrm{T}$ cell therapies (99). Fundamentally, cells require labeling to visualize them in vivo using technologies with exquisite sensitivities. Non-invasive radionuclide imaging by single photon emission computed tomography (SPECT) or positron emission tomography (PET) offers excellent sensitivity with absolute quantification and true 3D information while being translatable to the clinic. Labels can be introduced into cells via two fundamentally different methodologies, direct and indirect cell labeling (98).

So-called "direct cell labeling" employs ready-to-use contrast agents (e.g., organic fluorophores, quantum dots, iron oxide nanoparticles, ${ }^{19} \mathrm{~F}$-fluorinated contrast agents, chelated radiometals etc.), which are introduced into cells either due to the contrast agents being cell permeant, or through assisted uptake (e.g., by transfection or internalization). We previously showed that direct radiolabeling of polyclonal murine $\mathrm{CD}^{+} \mathrm{T}$ cells with ${ }^{99 \mathrm{~m}} \mathrm{Tc}$-hexamethylpropyleneamine oxime did not affect cell viability, but the radiolabeled cells could only be tracked for up to $24 \mathrm{~h}$ due to the short halflife of the radiolabel [half-life of ${ }^{99 \mathrm{~m}} \mathrm{Tc}$ is $6.01 \mathrm{~h}$; (100)]. This enabled the assessment of Treg biodistribution within a day of administration but precluded long-term tracking of Tregs. Longer half-life isotopes could provide this opportunity, albeit are not free of caveats. The SPECT isotope ${ }^{111} \mathrm{In}$ has been used clinically to follow directly labeled white blood cells for decades (101), but due to its decay properties it has also been associated with significant radiodamage (102). ${ }^{89} \mathrm{Zr}$ has a similar half-life as ${ }^{111} \mathrm{In}$ and was used to track cells for up to 2 weeks $(103,104)$. With clinical PET being more sensitive than SPECT, not least through the very recent development of total-body PET, which has been shown to be another 40-times more sensitive than conventional PET (105), ${ }^{89} \mathrm{Zr}$-labeling would result in the use of less radioactivity to achieve the same tracking results. However, radio-damage as a consequence of radioisotope incorporation into cells must be assessed, particularly in cell types such as $\mathrm{T}$ cells that are routinely ablated using radiation. Therefore, careful dosimetry considerations are required to assess both the preclinical and clinical feasibility of Treg tracking via this route [for caveats see (98)].

The alternative is "indirect cell labeling," whereby a genetically encoded reporter is ectopically introduced into the cells mostly by viral transduction to ensure genomic integration and thus stable long-term expression; transposon and gene editing represent alternative methodologies $(106,107)$. Reporter genes have critical advantages over direct labeling for cell tracking $(99,108)$. First, the observation period is independent of the contrast agent, for example, not affected by the half-life of a radioisotope. Second, genetic encoding avoids label dilution phenomena, which are limiting observation times in the case of fast-growing cells (e.g., expanding $\mathrm{T}$ cells). Third, genetic encoding circumvents complex direct cell labeling procedures and potential associated cell toxicities. A drawback of the indirect cell labeling approach is that it requires genetic engineering. However, this is not a concern for preclinical experimentation and not a concern for adoptive cell therapies that require genetic engineering to confer targeting specificity and/or efficacy, such as CAR-Treg therapy. Treg in vivo dynamics has been assessed preclinically using bioluminescence reporters $(109,110)$. Dawson et al. tracked HLA-A2 CAR-Tregs in vivo using bioluminescence and 
found that the peak of CAR-Treg infiltration to $\mathrm{A}^{+}$skin graft was 7 days post infusion (53). However, this imaging modality is not clinically translatable because of the nonhuman nature of luciferases, and the added disadvantages of optical imaging at depth (absorption, scatter) precluding reliable quantification. As foreign reporters can elicit an immune response and result in immune destruction of the administered therapeutic cells, a host-compatible reporter is preferable in this context. Host reporters are from the same species but endogenously expressed in only a very limited number of host tissues, and ideally at low levels to ensure favorable contrast (99). The most promising host reporters available for the purpose of Treg tracking in skin transplant models are the human sodium iodide symporter (NIS) (111) and the human prostate-specific membrane antigen (PSMA) (112), as neither of them is expressed in human or mouse dermis or epidermis. NIS offers the advantage of a generator-produced radiotracer $\left(\left[{ }^{99 \mathrm{~m}} \mathrm{Tc}\right] \mathrm{TcO}_{4}^{-}\right)$for SPECT imaging avoiding complex synthesis on each imaging day. Notably, there is also a clinical PET tracer available for NIS $\left(\left[{ }^{18} \mathrm{~F} \mathrm{BF}_{4}^{-}\right)\right.$, which is accessible via an automated synthesis protocol $(113,114)$. Notably, Volpe et al. have also demonstrated that NIS expression and use for imaging did not result in radiodamage-related negative effects in CAR$\mathrm{T}$ cells (115). In a proof-of-principle study employing retroviral transduction methodology, we demonstrated ex vivo engineering of murine Tregs to express a radionuclide imaging reporter and detected them $24 \mathrm{~h}$ post administration by SPECT imaging (116). However, so far long-term tracking of human Tregs has not been addressed using clinically translatable imaging technologies and remains an important area of future research to aid the development and clinical translation of adoptive Treg therapy.

\section{TRANSLATING CAR-TREGS TO THE CLINIC}

The quick evolution of CAR-T cells into clinic has informed the scientific community of the pitfalls and hurdles associated with delivering an effective, safe and reproducible treatment; applying the lessons to CAR-Treg therapy should accelerate their use in clinic. Fritsche et al. extensively reviewed optimized methods in manufacturing GMP-grade CAR-Tregs (117) but factors including generating "off-the-shelf" products, increasing in vivo persistence and eliminating CAR-associated toxicities are a few examples of hurdles to overcome and will be discussed next.

Developing next-generation, or "off-the-shelf," products is a focal point for clinical translation of CAR-T cells and, equally, must be considered for CAR-Treg therapy. Currently, the manufacturing process of autologous CAR-T cells for cancer patients incur a few paramount disadvantages, such as possible failure during manufacturing, and critically, the 3 week long process of developing the treatment which is a setback in highly proliferative malignancies [reviewed in (118)]. Time critical treatment delivery is not as big of a concern for CAR-Tregs in autoimmunity and solid organ transplant rejection. However, risk of failure due to low absolute numbers or functionally defective Tregs because of the disease, or interference from adjunct immunosuppressive medications need to be considered. Most importantly, the high cost incurred of manufacturing and delivery patient derived CAR-T cells has been a challenge for health care systems and needs to be considered if CAR-Treg therapy is to be translated into clinic. Previously, allogeneic CAR$T$ cells generated from "healthy donors" have been considered as a fast, scaled-up and decreased cost method of which high numbers of CAR-T cells can be produced per donor, with the added advantage of cryopreserving large batches, ready for treatment immediately. However, this gave rise to GvHD or clearance by the host's immune system (119). Different strategies have looked at generating manipulated "off the shelf" CAR-T cell products.

The use of gene editing as a tool for generating off the shelf CAR-T cells is very promising and can be translated to CAR-Treg therapy. This can be achieved by using transcription-activatorlike effector nucleases (TALENs) to knock out the TCR $\alpha$ chain (TRAC) or $\beta 2$ microglobulin of the MHC molecule, to prevent alloreactive T cells from inducing GvHD (120). CRISPR-Cas9 is another tool to replace the TCR $\alpha \beta$ with the CAR in the TRAC locus or $\beta 2$ microglobulin of the MHC molecule to minimize immunogenicity avoiding $\operatorname{GvHD}(121,122)$.

Concerns surrounding candidate patients who are on immunosuppressive regiments may also interfere or crosstalk with CAR-Treg efficacy. Drug such as antithymocyte globulin (ATG), cyclosporin, anti-CD25 and rapamycin are administered to transplant recipients and have an impact on Treg numbers and function. ATG reduces the absolute number of Tregs and high doses has been linked to impaired thymic Treg development in allogeneic HSCT (123). Cyclosporin and other calcineurin inhibitors (e.g., tacrolimus) suppress Treg activation and decrease FOXP3 expression but this can be restored by administration of IL-2 (124). We have shown in the ThRIL study the efficacy of Treg therapy in patients on immunosuppressive regimens including ATG and tacrolimus, which is encouraging for future CAR-Treg trials (17). In contrast, drugs such as sirolimus or everolimus, (rapamycin) inhibitors of the mTOR pathway may have a beneficial effect as used in combination with Tregs in the treatment of transplant patients as rapamycin is routinely used in the ex vivo expansion of Tregs and promote Tconv outgrowth (125).

\section{CONCLUDING REMARKS}

CAR-Tregs are the logical extension of polyclonal Treg therapy to enhance their efficacy by conferring antigen-specificity. It is an emerging area with not an insignificant amount of research required to develop and adapt existing CAR-Treg concepts and optimize them for successful clinical translation. As reviewed here the application of CAR-Tregs to the clinic needs further refinement. There is a need to maximize their suppressive function, their stability and understand better their homing capacity and longevity i.e., preventing CAR-Treg exhaustion. Such cell products raise another concern and this is the cost (126). Currently, treating a patient with anti-cancer CAR$\mathrm{T}$ cell therapy costs $\$ 400,000$ without the ancillary costs 
(127). Furthermore, the critical rate needed to manufacture personalized products, the failure to achieve the targeted cell numbers in some patients, and the heterogeneity of the cell products generated need to be overcome. However, the safety demonstrated with the clinical application of polyclonal Tregs and the pre-clinical data with CAR-Tregs has now generated investment in CAR-Treg therapy and several start-up companies have been funded, with the aim of applying CAR-Tregs to cure autoimmune diseases and induce transplantation tolerance. The first CAR-Treg clinical trial has been granted by UK MHRA authorization in a phase I/II clinical trial (STEADFAST) for kidney transplant patients. Progress in our understanding of the biology of Tregs, the ability of functional enhancements through genetic engineering, contribute to the excitement of this field of research.

\section{AUTHOR CONTRIBUTIONS}

YM participated in manuscript writing, editing and coordination of its submission. ST and CD contributed to manuscript

\section{REFERENCES}

1. Sakaguchi S, Yamaguchi T, Nomura T, Ono M. Regulatory T cells and immune tolerance. Cell. (2008) 133:775-87. doi: 10.1016/j.cell.2008.05.009

2. Itoh M, Takahashi T, Sakaguchi N, Kuniyasu Y, Shimizu J, Otsuka F, et al. Thymus and autoimmunity: production of $\mathrm{CD} 25+\mathrm{CD} 4+$ naturally anergic and suppressive $\mathrm{T}$ cells as a key function of the thymus in maintaining immunologic self-tolerance. J Immunol. (1999) 162:5317-26.

3. Polansky JK, Kretschmer K, Freyer J, Floess S, Garbe A, Baron U, et al. DNA methylation controls Foxp3 gene expression. Eur J Immunol. (2008) 38:1654-63. doi: 10.1002/eji.200838105

4. Lyon MF, Peters J, Glenister PH, Ball S, Wright E. The scurfy mouse mutant has previously unrecognized hematological abnormalities and resembles wiskott-aldrich syndrome. Proc Natl Acad Sci USA. (1990) 87:2433-7. doi: 10.1073/pnas.87.7.2433

5. Vandenbark AA, Offner $\mathrm{H}$. Critical evaluation of regulatory $\mathrm{T}$ cells in autoimmunity: are the most potent regulatory specificities being ignored? Immunology. (2008) 125:1-13. doi: 10.1111/j.1365-2567.2008. 02900.x

6. Abbas AK, Benoist C, Bluestone JA, Campbell DJ, Ghosh S, Hori S, et al. Regulatory T cells: recommendations to simplify the nomenclature. Nat Immunol. (2013) 14:307-8. doi: 10.1038/ni.2554

7. Singer A, Adoro S, Park JH. Lineage fate and intense debate: myths, models and mechanisms of CD4- versus CD8-lineage choice. Nat Rev Immunol. (2008) 8:788-801. doi: 10.1038/nri2416

8. Kretschmer K, Apostolou I, Hawiger D, Khazaie K, Nussenzweig MC, von Boehmer $\mathrm{H}$. Inducing and expanding regulatory $\mathrm{T}$ cell populations by foreign antigen. Nat Immunol. (2005) 6:1219-27. doi: 10.1038/ni1265

9. Romano M, Fanelli G, Albany CJ, Giganti G, Lombardi G. Past, present, and future of regulatory $\mathrm{T}$ cell therapy in transplantation and autoimmunity. Front Immunol. (2019) 10:43. doi: 10.3389/fimmu.2019.00043

10. Brunstein CG, Miller JS, Cao Q, McKenna DH, Hippen KL, Curtsinger J, et al. Infusion of ex vivo expanded T regulatory cells in adults transplanted with umbilical cord blood: safety profile and detection kinetics. Blood. (2011) 117:1061-70. doi: 10.1182/blood-2010-07-293795

11. Martelli MF, Di Ianni M, Ruggeri L, Falzetti F, Carotti A, Terenzi A, et al. HLA-haploidentical transplantation with regulatory and conventional T-cell adoptive immunotherapy prevents acute leukemia relapse. Blood. (2014) 124:638-44. doi: 10.1182/blood-2014-03-564401

12. Trzonkowski P, Dukat-Mazurek A, Bieniaszewska M, Marek-Trzonkowska N, Dobyszuk A, Juscinska J, et al. Treatment of graft-versus-host disease writing. RL, GF, and GL contributed to manuscript writing and editing. All authors contributed to the article and approved the submitted version.

\section{FUNDING}

The authors have received funding from the Medical Research Council (MRC), the British Heart Foundation (TG/16/2/32657 to GL), and Cancer Cancer Research UK (Multidisciplinary Project Award C48390/A21153 to GF). CD was funded by Societe Francophone de Transplantation and the European Society of Organ Transplantation. This work was further supported by the Department of Health (DoH) via the National Institute for Health Research (NIHR) Comprehensive Biomedical Research Centre award to King's Health Partners, and the Wellcome/EPSRC Centre for Medical Engineering (WT203148/Z/16/Z). Institutional Open Access funds to support article publication were also received. Views expressedare those of the authors and not necessarily those of the NHS, NIHR, or $\mathrm{DoH}$.

with naturally occurring T regulatory cells. Biodrugs. (2013) 27:605-14. doi: 10.1007/s40259-013-0050-5

13. Marek-Trzonkowska N, Mysliwiec M, Dobyszuk A, Grabowska M, Derkowska I, Juscinska J, et al. Therapy of type 1 diabetes with $\mathrm{CD} 4(+) \mathrm{CD} 25$ (high)CD127-regulatory $\mathrm{T}$ cells prolongs survival of pancreatic islets - results of one year follow-up. Clin Immunol. (2014) 153:23-30. doi: 10.1016/j.clim.2014.03.016

14. Bluestone JA, Buckner JH, Fitch M, Gitelman SE, Gupta S, Hellerstein M, et al. Type 1 diabetes immunotherapy using polyclonal regulatory T cells. Sci Transl Med. (2015) 7:315ra189. doi: 10.1126/scitranslmed.aad4134

15. Todo S, Yamashita K, Goto R, Zaitsu M, Nagatsu A, Oura T, et al. A pilot study of operational tolerance with a regulatory T-cell-based cell therapy in living donor liver transplantation. Hepatology. (2016) 64:632-43. doi: $10.1002 /$ hep. 28459

16. Chandran S, Tang Q, Sarwal M, Laszik ZG, Putnam AL, Lee K, et al. Polyclonal regulatory $\mathrm{T}$ cell therapy for control of inflammation in kidney transplants. Am J Transplant. (2017) 17:2945-54. doi: 10.1111/ajt.14415

17. Sanchez-Fueyo A, Whitehouse G, Grageda N, Cramp ME, Lim TY, Romano $\mathrm{M}$, et al. Applicability, safety, and biological activity of regulatory $\mathrm{T}$ cell therapy in liver transplantation. Am J Transplant. (2019) 20:1125-36. doi: 10.1111/ajt.15700

18. Sawitzki B, Harden PN, Reinke P, Moreau A, Hutchinson JA, Game DS, et al. Regulatory cell therapy in kidney transplantation (the ONE study): a harmonised design and analysis of seven nonrandomised, single-arm, phase 1/2A trials. Lancet. (2020) 395:1627-39. doi: $10.1016 / S 0140-6736(20) 30167-7$

19. Tang Q, Henriksen KJ, Bi M, Finger EB, Szot G, Ye J, et al. In vitro-expanded antigen-specific regulatory $\mathrm{T}$ cells suppress autoimmune diabetes. J Exp Med. (2004) 199:1455-65. doi: 10.1084/jem.20040139

20. Tarbell KV, Yamazaki S, Olson K, Toy P, Steinman RM. CD25+ CD4+ $\mathrm{T}$ cells, expanded with dendritic cells presenting a single autoantigenic peptide, suppress autoimmune diabetes. J Exp Med. (2004) 199:1467-77. doi: $10.1084 /$ jem.20040180

21. Sagoo P, Ali N, Garg G, Nestle FO, Lechler RI, Lombardi G. Human regulatory $\mathrm{T}$ cells with alloantigen specificity are more potent inhibitors of alloimmune skin graft damage than polyclonal regulatory T cells. Sci Transl Med. (2011) 3:83ra42. doi: 10.1126/scitranslmed.3002076

22. Putnam AL, Safinia N, Medvec A, Laszkowska M, Wray M, Mintz MA, et al. Clinical grade manufacturing of human alloantigen-reactive regulatory $\mathrm{T}$ cells for use in transplantation. Am J Transplant. (2013) 13:3010-20. doi: $10.1111 /$ ajt.12433 
23. Zheng J, Liu Y, Lau YL, Tu W. CD40-activated B cells are more potent than immature dendritic cells to induce and expand $\mathrm{CD} 4(+)$ regulatory $\mathrm{T}$ cells. Cell Mol Immunol. (2010) 7:44-50. doi: 10.1038/cmi.2009.103

24. Wright GP, Notley CA, Xue SA, Bendle GM, Holler A, Schumacher TN, et al. Adoptive therapy with redirected primary regulatory $\mathrm{T}$ cells results in antigen-specific suppression of arthritis. Proc Natl Acad Sci USA. (2009) 106:19078-83. doi: 10.1073/pnas.0907396106

25. Tsang JY, Tanriver Y, Jiang S, Xue SA, Ratnasothy K, Chen D, et al. Conferring indirect allospecificity on CD4+CD25+ tregs by TCR gene transfer favors transplantation tolerance in mice. J Clin Invest. (2008) 118:3619-28. doi: 10.1172/JCI33185

26. Brusko TM, Koya RC, Zhu S, Lee MR, Putnam AL, McClymont SA, et al. Human antigen-specific regulatory $\mathrm{T}$ cells generated by $\mathrm{T}$ cell receptor gene transfer. PLoS ONE. (2010) 5:e11726. doi: 10.1371/journal.pone.0011726

27. Hull CM, Nickolay LE, Estorninho M, Richardson MW, Riley JL, Peakman $\mathrm{M}$, et al. Generation of human islet-specific regulatory T cells by TCR gene transfer. J Autoimmun. (2017) 79:63-73. doi: 10.1016/j.jaut.2017.01.001

28. Kim YC, Zhang AH, Yoon J, Culp WE, Lees JR, Wucherpfennig KW, et al. Engineered MBP-specific human tregs ameliorate MOG-induced EAE through IL-2-triggered inhibition of effector T cells. J Autoimmun. (2018) 92:77-86. doi: 10.1016/j.jaut.2018.05.003

29. Herzog RW, Kuteyeva V, Saboungi R, Terhorst C, Biswas M. Reprogrammed $\mathrm{CD} 4(+) \mathrm{T}$ cells that express FoxP3(+) control inhibitory antibody formation in hemophilia A mice. Front Immunol. (2019) 10:274. doi: 10.3389/fimmu.2019.00274

30. Jaeckel E, von Boehmer H, Manns MP. Antigen-specific FoxP3-transduced T-cells can control established type 1 diabetes. Diabetes. (2005) 54:306-10. doi: $10.2337 /$ diabetes.54.2.306

31. Beavis PA, Gregory B, Green P, Cribbs AP, Kennedy A, Amjadi P, et al. Resistance to regulatory $\mathrm{T}$ cell-mediated suppression in rheumatoid arthritis can be bypassed by ectopic foxp3 expression in pathogenic synovial T cells. Proc Natl Acad Sci USA. (2011) 108:16717-22. doi: 10.1073/pnas.1112722108

32. Loser K, Hansen W, Apelt J, Balkow S, Buer J, Beissert S. In vitro-generated regulatory $\mathrm{T}$ cells induced by Foxp3-retrovirus infection control murine contact allergy and systemic autoimmunity. Gene Ther. (2005) 12:1294-304. doi: $10.1038 /$ sj.gt.3302567

33. Caruso HG, Hurton LV, Najjar A, Rushworth D, Ang S, Olivares S, et al. Tuning sensitivity of CAR to EGFR density limits recognition of normal tissue while maintaining potent antitumor activity. Cancer Res. (2015) 75:3505-18. doi: 10.1158/0008-5472.CAN-15-0139

34. Liu X, Jiang S, Fang C, Yang S, Olalere D, Pequignot EC, et al. Affinitytuned ErbB2 or EGFR chimeric antigen receptor $T$ cells exhibit an increased therapeutic index against tumors in mice. Cancer Res. (2015) 75:3596-607. doi: 10.1158/0008-5472.CAN-15-0159

35. Kershaw MH, Westwood JA, Parker LL, Wang G, Eshhar Z, Mavroukakis $\mathrm{SA}$, et al. A phase I study on adoptive immunotherapy using genemodified T cells for ovarian cancer. Clin Cancer Res. (2006) 12:6106-15. doi: 10.1158/1078-0432.CCR-06-1183

36. Bridgeman JS, Hawkins RE, Bagley S, Blaylock M, Holland M, Gilham $D E$. The optimal antigen response of chimeric antigen receptors harboring the CD3zeta transmembrane domain is dependent upon incorporation of the receptor into the endogenous TCR/CD3 complex. J Immunol. (2010) 184:6938-49. doi: 10.4049/jimmunol.0901766

37. US Food and Drug Administration. FDA approves CAR-T cell therapy to treat adults with certain types of large B-cell lymphoma. Silver Spring, MD: US Food and Drug Administration. (2017).

38. Maude SL, Teachey DT, Porter DL, Grupp SA. CD19-targeted chimeric antigen receptor T-cell therapy for acute lymphoblastic leukemia. Blood. (2015) 125:4017-23. doi: 10.1182/blood-2014-12-580068

39. Neelapu SS, Locke FL, Bartlett NL, Lekakis LJ, Miklos DB, Jacobson CA, et al. Axicabtagene ciloleucel CAR T-cell therapy in refractory large B-cell lymphoma. N Engl J Med. (2017) 377:2531-44. doi: 10.1056/NEJMoa1707447

40. Maude SL, Laetsch TW, Buechner J, Rives S, Boyer M, Bittencourt H, et al. Tisagenlecleucel in children and young adults with B-cell lymphoblastic leukemia. N Engl J Med. (2018) 378:439-48. doi: 10.1056/NEJMoa1709866

41. Schuster SJ, Svoboda J, Chong EA, Nasta SD, Mato AR, Anak O, et al. Chimeric antigen receptor T cells in refractory B-cell lymphomas. $N$ Engl J Med. (2017) 377:2545-54. doi: 10.1056/NEJMoa1708566
42. Linette GP, Stadtmauer EA, Maus MV, Rapoport AP, Levine BL, Emery L, et al. Cardiovascular toxicity and titin cross-reactivity of affinityenhanced T cells in myeloma and melanoma. Blood. (2013) 122:863-71. doi: 10.1182/blood-2013-03-490565

43. Saudemont A, Jespers L, Clay T. Current status of gene engineering cell therapeutics. Front Immunol. (2018) 9:153. doi: 10.3389/fimmu.2018.00153

44. Ellebrecht CT, Bhoj VG, Nace A, Choi EJ, Mao X, Cho MJ, et al. Reengineering chimeric antigen receptor $\mathrm{T}$ cells for targeted therapy of autoimmune disease. Science. (2016) 353:179-84. doi: $10.1126 /$ science.aaf6756

45. Elinav E, Adam N, Waks T, Eshhar Z. Amelioration of colitis by genetically engineered murine regulatory $\mathrm{T}$ cells redirected by antigenspecific chimeric receptor. Gastroenterology. (2009) 136:1721-31. doi: 10.1053/j.gastro.2009.01.049

46. Blat D, Zigmond E, Alteber Z, Waks T, Eshhar Z. Suppression of murine colitis and its associated cancer by carcinoembryonic antigenspecific regulatory T cells. Mol Ther. (2014) 22:1018-28. doi: 10.1038/mt. 2014.41

47. Skuljec J, Chmielewski M, Happle C, Habener A, Busse M, Abken H, et al. Chimeric antigen receptor-redirected regulatory $\mathrm{T}$ cells suppress experimental allergic airway inflammation, a model of asthma. Front Immunol. (2017) 8:1125. doi: 10.3389/fimmu.2017.01125

48. Tenspolde M, Zimmermann K, Weber LC, Hapke M, Lieber M, Dywicki J, et al. Regulatory $\mathrm{T}$ cells engineered with a novel insulin-specific chimeric antigen receptor as a candidate immunotherapy for type 1 diabetes. $J$ Autoimmun. (2019) 103:102289. doi: 10.1016/j.jaut.2019.05.017

49. Zhang AH, Yoon J, Kim YC, Scott DW. Targeting antigen-specific B cells using antigen-expressing transduced regulatory T cells. J Immunol. (2018) 201:1434-41. doi: 10.4049/jimmunol.1701800

50. MacDonald KG, Hoeppli RE, Huang Q, Gillies J, Luciani DS, Orban PC, et al. Alloantigen-specific regulatory $\mathrm{T}$ cells generated with a chimeric antigen receptor. J Clin Invest. (2016) 126:1413-24. doi: 10.1172/JCI82771

51. Boardman DA, Philippeos C, Fruhwirth GO, Ibrahim MA, Hannen RF, Cooper D, et al. Expression of a chimeric antigen receptor specific for donor HLA class I enhances the potency of human regulatory $\mathrm{T}$ cells in preventing human skin transplant rejection. Am J Transplant. (2017) 17:931-43. doi: 10.1111/ajt.14185

52. Noyan F, Zimmermann K, Hardtke-Wolenski M, Knoefel A, Schulde E, Geffers R, et al. Prevention of allograft rejection by use of regulatory T cells with an MHC-specific chimeric antigen receptor. Am J Transplant. (2017) 17:917-30. doi: 10.1111/ajt.14175

53. Dawson NA, Lamarche C, Hoeppli RE, Bergqvist P, Fung VC, McIver $\mathrm{E}$, et al. Systematic testing and specificity mapping of alloantigen-specific chimeric antigen receptors in regulatory T cells. JCI Insight. (2019) 4:10.1172/jci.insight.123672. doi: 10.1172/jci.insight. 123672

54. Sicard A, Lamarche C, Speck M, Wong M, Rosado-Sanchez I, Blois, et al. Donor-specific chimeric antigen receptor tregs limit rejection in naive but not sensitized allograft recipients. Am J Transplant. (2020) 20:1562-73. doi: 10.1111/ajt.15787

55. Sadelain M, Brentjens R, Riviere I. The basic principles of chimeric antigen receptor design. Cancer Discov. (2013) 3:388-98. doi: 10.1158/2159-8290.CD-12-0548

56. Zhang P, Gao F, Wang Q, Wang X, Zhu F, Ma C, et al. Agonistic anti$4-1 \mathrm{BB}$ antibody promotes the expansion of natural regulatory $\mathrm{T}$ cells while maintaining Foxp3 expression. Scand J Immunol. (2007) 66:435-40. doi: 10.1111/j.1365-3083.2007.01994.x

57. Long AH, Haso WM, Shern JF, Wanhainen KM, Murgai M, Ingaramo $\mathrm{M}$, et al. 4-1BB co-stimulation ameliorates $\mathrm{T}$ cell exhaustion induced by tonic signaling of chimeric antigen receptors. Nat Med. (2015) 21:581-90. doi: $10.1038 / \mathrm{nm} .3838$

58. Song DG, Ye Q, Carpenito C, Poussin M, Wang LP, Ji C, et al. in vivo persistence, tumor localization, and antitumor activity of CARengineered $\mathrm{T}$ cells is enhanced by co-stimulatory signaling through CD137 (4-1BB). Cancer Res. (2011) 71:4617-27. doi: 10.1158/0008-5472.CAN11-0422

59. Li G, Boucher JC, Kotani H, Park K, Zhang Y, Shrestha B, et al. 4-1BB enhancement of CAR $\mathrm{T}$ function requires NF-kappaB and TRAFs. JCI Insight. (2018) 3:10.1172/jci.insight.121322. doi: 10.1172/jci.insight.121322 
60. Ito T, Wang YH, Duramad O, Hanabuchi S, Perng OA, Gilliet M, et al. OX40 ligand shuts down IL-10-producing regulatory T cells. Proc Natl Acad Sci USA. (2006) 103:13138-43. doi: 10.1073/pnas.0603107103

61. $\mathrm{Vu}$ MD, Xiao X, Gao W, Degauque N, Chen M, Kroemer A, et al. OX40 costimulation turns off Foxp3+ tregs. Blood. (2007) 110:2501-10. doi: 10.1182/blood-2007-01-070748

62. So T, Croft M. Cutting edge: OX40 inhibits TGF-beta- and antigen-driven conversion of naive CD4 T cells into CD25+Foxp3+ T cells. J Immunol. (2007) 179:1427-30. doi: 10.4049/jimmunol.179.3.1427

63. Rogers PR, Song J, Gramaglia I, Killeen N, Croft M. OX40 promotes bcl-xL and bcl-2 expression and is essential for long-term survival of CD4 T cells. Immunity. (2001) 15:445-55. doi: 10.1016/S1074-7613(01)00191-1

64. Song J, Salek-Ardakani S, Rogers PR, Cheng M, Van Parijs L, Croft M. The co-stimulation-regulated duration of PKB activation controls $\mathrm{T}$ cell longevity. Nat Immunol. (2004) 5:150-8. doi: 10.1038/ni1030

65. Song A, Tang X, Harms KM, Croft M. OX40 and bcl-xL promote the persistence of CD8 T cells to recall tumor-associated antigen. J Immunol. (2005) 175:3534-41. doi: 10.4049/jimmunol.175.6.3534

66. Hombach AA, Heiders J, Foppe M, Chmielewski M, Abken H. OX40 costimulation by a chimeric antigen receptor abrogates $\mathrm{CD} 28$ and IL-2 induced IL-10 secretion by redirected CD4(+) T cells. Oncoimmunology. (2012) 1:458-66. doi: 10.4161/onci.19855

67. Hombach AA, Abken H. Co-stimulation by chimeric antigen receptors revisited the $\mathrm{T}$ cell antitumor response benefits from combined CD28-OX40 signalling. Int J Cancer. (2011) 129:2935-44. doi: 10.1002/ijc.25960

68. Dong C, Juedes AE, Temann UA, Shresta S, Allison JP, Ruddle NH, et al. ICOS co-stimulatory receptor is essential for T-cell activation and function. Nature. (2001) 409:97-101. doi: 10.1038/35051100

69. Hutloff A, Dittrich AM, Beier KC, Eljaschewitsch B, Kraft R, Anagnostopoulos I, et al. ICOS is an inducible T-cell co-stimulator structurally and functionally related to CD28. Nature. (1999) 397:263-6. doi: $10.1038 / 16717$

70. Rudd CE, Schneider H. Unifying concepts in CD28, ICOS and CTLA4 coreceptor signalling. Nat Rev Immunol. (2003) 3:544-56. doi: 10.1038/nri1131

71. McAdam AJ, Chang TT, Lumelsky AE, Greenfield EA, Boussiotis VA, DukeCohan JS, et al. Mouse inducible co-stimulatory molecule (ICOS) expression is enhanced by $\mathrm{CD} 28$ co-stimulation and regulates differentiation of $\mathrm{CD} 4+$ T cells. J Immunol. (2000) 165:5035-40. doi: 10.4049/jimmunol.165.9.5035

72. Guedan S, Chen X, Madar A, Carpenito C, McGettigan SE, Frigault MJ, et al. ICOS-based chimeric antigen receptors program bipolar TH17/TH1 cells. Blood. (2014) 124:1070-80. doi: 10.1182/blood-2013-10-535245

73. Hendriks J, Gravestein LA, Tesselaar K, van Lier RA, Schumacher TN, Borst J. CD27 is required for generation and long-term maintenance of $\mathrm{T}$ cell immunity. Nat Immunol. (2000) 1:433-40. doi: 10.1038/80877

74. Song DG, Powell DJ. Pro-survival signaling via CD27 costimulation drives effective CAR T-cell therapy. Oncoimmunology. (2012) 1:547-49. doi: $10.4161 /$ onci.19458

75. Arroyo Hornero R, Betts GJ, Sawitzki B, Vogt K, Harden PN, Wood KJ. CD45RA distinguishes CD4+CD25+CD127-/low TSDR demethylated regulatory $\mathrm{T}$ cell subpopulations with differential stability and susceptibility to tacrolimus-mediated inhibition of suppression. Transplantation. (2017) 101:302-9. doi: 10.1097/TP.0000000000001278

76. Monjezi R, Miskey C, Gogishvili T, Schleef M, Schmeer M, Einsele $\mathrm{H}$, et al. Enhanced CAR T-cell engineering using non-viral sleeping beauty transposition from minicircle vectors. Leukemia. (2017) 31:186-94. doi: 10.1038/leu.2016.180

77. Vormittag P, Gunn R, Ghorashian S, Veraitch FS. A guide to manufacturing CAR T cell therapies. Curr Opin Biotechnol Biotechnol. (2018) 53:164-81. doi: 10.1016/j.copbio.2018.01.025

78. Kumar P, Bhattacharya P, Prabhakar BS. A comprehensive review on the role of co-signaling receptors and treg homeostasis in autoimmunity and tumor immunity. J Autoimmun. (2018) 95:77-99. doi: 10.1016/j.jaut.2018.08.007

79. Hegde M, Corder A, Chow KK, Mukherjee M, Ashoori A, Kew Y, et al. Combinational targeting offsets antigen escape and enhances effector functions of adoptively transferred T cells in glioblastoma. Mol Ther. (2013) 21:2087-101. doi: 10.1038/mt.2013.185

80. Ruella M, Barrett DM, Kenderian SS, Shestova O, Hofmann TJ, Perazzelli $\mathrm{J}$, et al. Dual CD19 and CD123 targeting prevents antigen-loss relapses after CD19-directed immunotherapies. J Clin Invest. (2016) 126:3814-26. doi: 10.1172/JCI87366

81. Zah E, Lin MY, Silva-Benedict A, Jensen MC, Chen YY. T cells expressing CD19/CD20 bispecific chimeric antigen receptors prevent antigen escape by malignant B cells. Cancer Immunol Res. (2016) 4:498-508. doi: 10.1158/2326-6066.CIR-15-0231

82. Kloss CC, Condomines M, Cartellieri M, Bachmann M, Sadelain M. Combinatorial antigen recognition with balanced signaling promotes selective tumor eradication by engineered T cells. Nat Biotechnol. (2013) 31:71-5. doi: 10.1038/nbt.2459

83. Roybal KT, Rupp LJ, Morsut L, Walker WJ, McNally KA, Park JS, et al. Precision tumor recognition by $\mathrm{T}$ cells with combinatorial antigen-sensing circuits. Cell. (2016) 164:770-9. doi: 10.1016/j.cell.2016.01.011

84. Grada Z, Hegde M, Byrd T, Shaffer DR, Ghazi A, Brawley VS, et al. TanCAR: A novel bispecific chimeric antigen receptor for cancer immunotherapy. Mol Ther Nucleic Acids. (2013) 2:e105. doi: 10.1038/mtna.2013.32

85. Jia H, Wang Z, Wang Y, Liu Y, Dai H, Tong C, et al. Haploidentical CD19/CD22 bispecific CAR-T cells induced MRD-negative remission in a patient with relapsed and refractory adult B-ALL after haploidentical hematopoietic stem cell transplantation. J Hematol Onco. (2019) 12:57-019-0741-6. doi: 10.1186/s13045-019-0741-6

86. Jensen MC, Riddell SR. Design and implementation of adoptive therapy with chimeric antigen receptor-modified T cells. Immunol Rev. (2014) 257:127-44. doi: 10.1111/imr.12139

87. Koristka S, Kegler A, Bergmann R, Arndt C, Feldmann A, Albert S, et al. Engrafting human regulatory $\mathrm{T}$ cells with a flexible modular chimeric antigen receptor technology. J Autoimmun. (2018) 90:116-31. doi: 10.1016/j.jaut.2018.02.006

88. Darowski D, Kobold S, Jost C, Klein C. Combining the best of two worlds: highly flexible chimeric antigen receptor adaptor molecules (CAR-adaptors) for the recruitment of chimeric antigen receptor T cells. Mabs. (2019) 11:621-31. doi: 10.1080/19420862.2019.1596511

89. Pierini A, Iliopoulou BP, Peiris H, Perez-Cruz M, Baker J, Hsu K, et al. $\mathrm{T}$ cells expressing chimeric antigen receptor promote immune tolerance. JCI Insight. (2017) 2:10.1172/jci.insight.92865. doi: 10.1172/jci.insight. 92865

90. Boroughs AC, Larson RC, Choi BD, Bouffard AA, Riley LS, Schiferle E, et al. Chimeric antigen receptor co-stimulation domains modulate human regulatory T cell function. JCI Insight. (2019) 5:10.1172/jci.insight.126194. doi: 10.1172/jci.insight.126194

91. Quintarelli C, Orlando D, Boffa I, Guercio M, Polito VA, Petretto A, et al. Choice of co-stimulatory domains and of cytokines determines CAR T-cell activity in neuroblastoma. Oncoimmunology. (2018) 7:e1433518. doi: 10.1080/2162402X.2018.1433518

92. Wang X, Chang WC, Wong CW, Colcher D, Sherman M, Ostberg JR, et al. A transgene-encoded cell surface polypeptide for selection, in vivo tracking, and ablation of engineered cells. Blood. (2011) 118:1255-63. doi: 10.1182/blood-2011-02-337360

93. Philip B, Kokalaki E, Mekkaoui L, Thomas S, Straathof K, Flutter B, et al. A highly compact epitope-based marker/suicide gene for easier and safer T-cell therapy. Blood. (2014) 124:1277-87. doi: 10.1182/blood-2014-01545020

94. Straathof KC, Pule MA, Yotnda P, Dotti G, Vanin EF, Brenner MK, et al. An inducible caspase 9 safety switch for T-cell therapy. Blood. (2005) 105:4247-54. doi: 10.1182/blood-2004-11-4564

95. Caruso M, Panis Y, Gagandeep S, Houssin D, Salzmann JL, Klatzmann D. Regression of established macroscopic liver metastases after in situ transduction of a suicide gene. Proc Natl Acad Sci USA. (1993) 90:7024-8. doi: $10.1073 /$ pnas.90.15.7024

96. Di Stasi A, Tey SK, Dotti G, Fujita Y, Kennedy-Nasser A, Martinez C, et al. Inducible apoptosis as a safety switch for adoptive cell therapy. $\mathrm{N} \mathrm{Engl} \mathrm{J} \mathrm{Med.}$ (2011) 365:1673-83. doi: 10.1056/NEJMoal106152

97. Juno JA, van Bockel D, Kent SJ, Kelleher AD, Zaunders JJ, Munier CM. Cytotoxic CD4 T cells-friend or foe during viral infection? Front Immunol. (2017) 8:19. doi: 10.3389/fimmu.2017.00019

98. Iafrate M, Fruhwirth GO. How non-invasive in vivo cell tracking supports the development and translation of cancer immunotherapies. Front Physiol. (2020) 11:154. doi: 10.3389/fphys.2020.00154 
99. Ashmore-Harris C, Iafrate M, Saleem A, Fruhwirth GO. Non-invasive reporter gene imaging of cell therapies, including T cells and stem cells. Mol Ther. (2020) 28:1392-416. doi: 10.1016/j.ymthe.2020.03.016

100. Sharif-Paghaleh E, Leech J, Sunassee K, Ali N, Sagoo P, Lechler RI, et al. Monitoring the efficacy of dendritic cell vaccination by early detection of (99m) tc-HMPAO-labeled CD4(+) T cells. Eur J Immunol. (2014) 44:2188-91. doi: 10.1002/eji.201344337

101. Love C, Palestro CJ. Radionuclide imaging of infection. J Nucl Med Technol. (2004) 32:47-57; quiz 58-9. Available online at: http://tech.snmjournals.org/ content/32/2/47.long

102. Roca M, de Vries EF, Jamar F, Israel O, Signore A. Guidelines for the labeling of leucocytes with (111)in-oxine. Inflammation/Infection taskgroup of the european association of nuclear medicine. Eur J Nucl Med Mol Imaging. (2010) 37:835-41. doi: 10.1007/s00259-010-1393-5

103. Charoenphun P, Meszaros LK, Chuamsaamarkkee K, Sharif-Paghaleh E, Ballinger JR, Ferris TJ, et al. (89)zr]oxinate4 for long-term in vivo cell tracking by positron emission tomography. Eur J Nucl Med Mol Imaging. (2015) 42:278-87. doi: 10.1007/s00259-014-2945-x

104. Sato N, Wu H, Asiedu KO, Szajek LP, Griffiths GL, Choyke PL. (89)zr-oxine complex PET cell imaging in monitoring cell-based therapies. Radiology. (2015) 275:490-500. doi: 10.1148/radiol.15142849

105. Cherry SR, Jones T, Karp JS, Qi J, Moses WW, et al. Total-body PET: maximizing sensitivity to create new opportunities for clinical research and patient care. J Nucl Med. (2018) 59:3-12. doi: 10.2967/jnumed.116.184028

106. Li W, Prazak L, Chatterjee N, Gruninger S, Krug L, Theodorou D, et al. Activation of transposable elements during aging and neuronal decline in drosophila. Nat Neurosci. (2013) 16:529-31. doi: 10.1038/nn.3368

107. Bressan RB, Dewari PS, Kalantzaki M, Gangoso E, Matjusaitis M, GarciaDiaz C, et al. Efficient CRISPR/Cas9-assisted gene targeting enables rapid and precise genetic manipulation of mammalian neural stem cells. Development. (2017) 144:635-648. doi: 10.1242/dev.140855

108. Volpe A, Kurtys E, Fruhwirth GO. Cousins at work: how combining medical with optical imaging enhances in vivo cell trackin. Int J Biochem Cell Biol. (2018) 102:40-50. doi: 10.1016/j.biocel.2018.06.008

109. Nguyen VH, Zeiser R, Dasilva DL, Chang DS, Beilhack A, Contag $\mathrm{CH}$, et al. in vivo dynamics of regulatory $\mathrm{T}$-cell trafficking and survival predict effective strategies to control graft-versus-host disease following allogeneic transplantation. Blood. (2007) 109:2649-56. doi: 10.1182/blood-2006-08-044529

110. Suffner J, Hochweller K, Kuhnle MC, Li X, Kroczek RA, Garbi $\mathrm{N}$, et al. Dendritic cells support homeostatic expansion of Foxp3+ regulatory T cells in Foxp3.LuciDTR mice. J Immunol. (2010) 184:1810-20. doi: 10.4049/jimmunol.0902420

111. Portulano C, Paroder-Belenitsky M, Carrasco N. The Na+/I- symporter (NIS): mechanism and medical impact. Endocr Rev. (2014) 35:106-49. doi: 10.1210/er.2012-1036

112. Minn I, Huss DJ, Ahn HH, Chinn TM, Park A, Jones J, et al. Imaging CAR T cell therapy with PSMA-targeted positron emission tomography. Sci Adv. (2019) 5:eaaw5096. doi: 10.1126/sciadv.aaw5096

113. O’Doherty J, Jauregui-Osoro M, Brothwood T, Szyszko T, Marsden PK, O'Doherty MJ, et al. ${ }^{18} \mathrm{~F}$-tetrafluoroborate, a PET probe for imaging Sodium/Iodide symporter expression: Whole-body biodistribution, safety, and radiation dosimetry in thyroid cancer patients. J Nucl Med. (2017) 58:1666-71. doi: 10.2967/jnumed.117.192252

114. Volpe A, Man F, Lim L, Khoshnevisan A, Blower J, Blower PJ, et al. Radionuclide-fluorescence reporter gene imaging to track tumor progression in rodent tumor models. J Vis Exp. (2018) 133:57088. doi: 10.3791/57088

115. Volpe A, Lang C, Lim L, Man F, Kurtys E, Ashmore-Harris C. et al. Spatiotemporal PET Imaging Reveals Differences in CAR-T Tumor
Retention in Triple-Negative Breast Cancer Models. Mol Ther. (2020) 28. doi: 10.1016/j.ymthe.2020.06.028

116. Sharif-Paghaleh E, Sunassee K, Tavare R, Ratnasothy K, Koers A, Ali N, et al. in vivo SPECT reporter gene imaging of regulatory T cells. PLoS ONE. (2011) 6:e25857. doi: 10.1371/journal.pone.0025857

117. Fritsche E, Volk HD, Reinke P, Abou-El-Enein M. Toward an optimized process for clinical manufacturing of CAR-treg cell therapy. Trends Biotechnol. (2020). doi: 10.1016/j.tibtech.2019.12.009. [Epub ahead of print].

118. Kohl U, Arsenieva S, Holzinger A, Abken H. CAR T cells in trials: Recent achievements and challenges that remain in the production of modified T cells for clinical applications. Hum Gene Ther. (2018) 29:559-68. doi: 10.1089/hum.2017.254

119. Butler CL, Valenzuela NM, Thomas KA, Reed EF. Not all antibodies are created equal: Factors that influence antibody mediated rejection. J Immunol Res. (2017) 2017:7903471. doi: 10.1155/2017/7903471

120. Poirot L, Philip B, Schiffer-Mannioui C, Le Clerre D, Chion-Sotinel I, Derniame S, et al. Multiplex genome-edited T-cell manufacturing platform for "off-the-shelf” adoptive T-cell immunotherapies. Cancer Res. (2015) 75:3853-64. doi: 10.1158/0008-5472.CAN-14-3321

121. Eyquem J, Mansilla-Soto J, Giavridis T, van der Stegen SJ, Hamieh $\mathrm{M}$, Cunanan KM, et al. Targeting a CAR to the TRAC locus with CRISPR/Cas9 enhances tumour rejection. Nature. (2017) 543:113-7. doi: 10.1038 /nature21405

122. Liu X, Ranganathan R, Jiang S, Fang C, Sun J, Kim S, et al. A chimeric switch-receptor targeting PD1 augments the efficacy of second-generation CAR T cells in advanced solid tumors. Cancer Res. (2016) 76:1578-90. doi: 10.1158/0008-5472.CAN-15-2524

123. Gurkan S, Luan Y, Dhillon N, Allam SR, Montague T, Bromberg JS, et al. Immune reconstitution following rabbit antithymocyte globulin. Am J Transplant. (2010) 10:2132-41. doi: 10.1111/j.1600-6143.2010.03210.x

124. Satake A, Schmidt AM, Archambault A, Leichner TM, Wu GF, Kambayashi T. Differential targeting of IL-2 and T cell receptor signaling pathways selectively expands regulatory $\mathrm{T}$ cells while inhibiting conventional $\mathrm{T}$ cells. J Autoimmun. (2013) 44:13-20. doi: 10.1016/j.jaut.2013.06.009

125. Scotta C, Esposito M, Fazekasova H, Fanelli G, Edozie FC, Ali N, et al. Differential effects of rapamycin and retinoic acid on expansion, stability and suppressive qualities of human CD4(+)CD25(+)FOXP3(+) $\mathrm{T}$ regulatory cell subpopulations. Haematologica. (2013) 98:1291-9. doi: 10.3324/haematol.2012.074088

126. Ruella M, Kenderian SS. Next-generation chimeric antigen receptor T-cell therapy: going off the shelf. Biodrugs. (2017) 31:473-81. doi: 10.1007/s40259-017-0247-0

127. Bach PB. National coverage analysis of CAR-T therapies - policy, evidence, and payment. N Engl J Med. (2018) 379:1396-8. doi: 10.1056/NEJMp1807382

Conflict of Interest: The authors declare that YM and ST are employed by Quell Therapeutics. GL is co-Founder of Quell Therapeutics.

The remaining authors declare that the research was conducted in the absence of any commercial or financial relationships that could be construed as a potential conflict of interest.

Copyright (c) 2020 Mohseni, Tung, Dudreuilh, Lechler, Fruhwirth and Lombardi. This is an open-access article distributed under the terms of the Creative Commons Attribution License (CC BY). The use, distribution or reproduction in other forums is permitted, provided the original author(s) and the copyright owner(s) are credited and that the original publication in this journal is cited, in accordance with accepted academic practice. No use, distribution or reproduction is permitted which does not comply with these terms. 


\section{GLOSSARY}

$\mathbf{A}^{\mathbf{b}}$ : mouse MHC Class II molecule.

Aurora B kinase: a protein involved in the cell cycle; it functions in attaching the mitotic spindle to the centromere.

Bcl-2 (B-cell lymphoma 2): a protein, which regulates programmed cell death; anti-apoptotic protein that functions by preventing mitochondrial apoptogenic factors such as cytochrome $\mathrm{c}$ and apoptosis-inducing factor (AIF) to be released into the cytoplasm.

Bcl-xL (B-cell lymphoma-extra large): a protein that regulates programmed cell death in a similar manner as Bcl-2.

GvHD (Graft-vs.-host disease): an immune condition that occurs after transplant procedures when immune cells from the donor (known as the graft or graft cells) attack the recipient patient host's tissues; the disease is a side effect that is common after an allogeneic bone marrow transplant (stem cell transplant).

CRISPR/Cas9 (the clustered regularly interspaced short palindromic repeats system): combines a nuclease and a short RNA; specificity depends on RNA-DNA base pairing whereby the RNA is complementary to the genomic target DNA. The system most commonly uses Cas9, delivering the nuclease to the target site.

HuEGFRt: a human epidermal growth factor receptor (EGFR) polypeptide synthesized for cell selection by binding of an anti-EGFR monoclonal antibody.

Human FK506 binding protein-12: a $12 \mathrm{kD}$ cytosolic protein expressed ubiquitously; functions as a molecular chaperone for protein folding.

Immunodysregulation polyendocrinopathy enteropathy $\mathrm{X}$-linked (also known as IPEX): a rare disease associated with FOXP3 dysfunction, leading to Treg impairment and severe autoimmunity.
PSMA (Prostate-specific membrane antigen): a protein specifically expressed in prostate tissue carcinomas derived from it.

RQR8: the protein product of a suicide gene; more speciofically, a 136 amino acid construct, which enables selection with the cliniMACS CD34 system and in vivo depletion of the administered cells with rituximab.

Scurfy mouse: due to a mutation in the Foxp3 transcription factor, Scurfy mice lack regulatory T-cells that maintain selftolerance of the immune system.

PET (Positron Emission Tomography): a radionuclide 3D imaging modality used in the clinic; suitable radionuclides are incorporated into radiopharmaceuticals, which are then used to image specific biological process in vivo. The radioisotope must be a positron emitter, whose emitted positrons combine with electrons to produce two gamma rays pointing into opposite directions; these gamma rays are detected by the instrument and via reconstruction algorithms a 3D image is formed.

SPECT (Single Photon Emission Computed Tomography): a radionuclide $3 \mathrm{D}$ imaging modality used in the clinic; radionuclides are incorporates into radiopharmaceuticals, which are then used to image specific biological processes. The radioisotope must be a suitable gamma ray emitter; gamma rays pass through a collimator and are detected prior to econstruction and 3D image formation.

Survivin: a protein that regulates apoptosis and the cell cycle; it functions alongside aurora B kinase in facilitating completion of the cell cycle. Survivin forms a chromosomal passenger complex that regulates chromosome-microtubule attachment, proper spindle assembly and occurrence.

TSDR (Treg-specific demethylated region): an evolutionarily conserved element within the FOXP3 locus. 